\title{
Uso da Água por Plantas híbridas ou Convencionais de ARroz IRRIGADO $^{1}$
}

\author{
Water Use by Hybrid and Conventional Rice Plants \\ CONCENÇO, G. ${ }^{2}$, SANT’ANNA, S.J.. ${ }^{3}$, SCHWANKE, A.M.L. ${ }^{4}$, GALON, L. ${ }^{5}$, FERREIRA, E.A. ${ }^{5}$, \\ ASPIAZÚ, I. ${ }^{5}$, SILVA, A.F. ${ }^{5}$ e FERREIRA, F.A. ${ }^{6}$
}

\begin{abstract}
RESUMO - Objetivou-se com este trabalho avaliar as caracteristicas associadas à eficiência do uso da água em plantas de arroz irrigado, híbridas ou convencionais. O experimento foi instalado em casa de vegetação, em delineamento experimental de blocos casualizados em esquema fatorial $2 \times 6$, com quatro repetições. Os tratamentos constaram de uma planta de arroz da variedade BRS Pelota (convencional) ou Inov (híbrida) no centro da unidade experimental, que competia com $0,1,2,3,4$ ou 5 plantas da variedade BRS Pelota na periferia da unidade experimental, de acordo com o tratamento. Aos $50 \mathrm{DAE}$, foram realizadas as avaliações de massa seca da parte aérea, condutância estomática de vapores de água, temperatura da folha e taxa de transpiração, sendo calculada ainda a eficiência do uso da água pela relação entre quantidade de $\mathrm{CO}_{2}$ fixado pela fotossintese e quantidade de água transpirada. Plantas da variedade hibrida foram superiores ou não diferiram das convencionais quanto à eficiência do uso da água.
\end{abstract}

Palavras-chave: Oryza sativa, competição, fisiologia, hibridação

\begin{abstract}
The objective of this work was to evaluate the characteristics associated to water use efficiency in hybrid or conventional rice plants. The trial was installed under greenhouse conditions, in a completely randomized block design and factorial scheme $2 \times 6$, with four replications. The treatments consisted of one hybrid (Inov) or conventional (BRS Pelota) rice plant at the center of the plot surrounded by $0,1,2,3,4$, or 5 conventional (BRS Pelota) plants. Fifty days after emergence, shoot dry mass, stomatal conductance of water vapor, leaftemperature and transpiration rates were evaluated, as well as water use efficiency through the relation between the photosynthesis and transpiration rates. Hybrid rice plants were superior to, or did not differ from, the conventional plants in relation to water use efficiency.
\end{abstract}

Keywords: Oryza sativa, competition, physiology, hybridization.

\section{INTRODUÇÃO}

A cultura do arroz irrigado ocupa área superior a um milhão de hectares somente no Estado do Rio Grande do Sul (Fleck et al., 2008). Nessa cultura, há grande dificuldade de diferenciar o arroz cultivado do capim-arroz ou do arroz daninho, sobretudo quando em estádios jovens de crescimento. Assim, o uso de maquinários de última geração é consequência da dificuldade de controle das plantas daninhas presentes nas lavouras, que requerem a aplicação de herbicidas como método de controle em detrimento de outras alternativas de manejo. Várias opções existem atualmente para minimizar a interferência das plantas

Recebido para publicação em 4.3.2008 e na forma revisada em 15.5.2009.

2 Engo-Agr ${ }^{\circ}$, D.Sc. em Fitotecnia pela Universidade Federal de Viçosa - UFV, International Agronomist da Valmont Inc., <gconcenco@yahoo.com.br>; ${ }^{3}$ Engo-Agr ${ }^{\underline{0}}$, Universidade Federal de Viçosa - UFV; ${ }^{4}$ Eng ${ }^{0}$ Agr ${ }^{0}$, M.Sc., Ricetec; ${ }^{5}$ Doutorando em Fitotecnia, Dep. de Fitotecnia - DFT/UFV; ${ }^{6}$ Prof. do Dep. de Fitotecnia - DFT/UFV.

Planta Daninha, Viçosa-MG, v. 27, n. 3, p. 447-453, 2009 
daninhas na cultura do arroz; entre elas, destaca-se o uso de variedades melhoradas, que possuem, naturalmente, maior potencial de competição pelos recursos do ambiente.

A competição entre as plantas daninhas e o arroz pode afetar quantitativa e qualitativamente a produção do cereal, pois modifica a eficiência de aproveitamento dos recursos disponiveis no ambiente (Sinclair et al., 1975; Melo et al., 2006). Desse modo, o vigor híbrido é uma das características que proporcionam à planta maior capacidade de aproveitamento dos recursos e maior taxa de crescimento. Atualmente, trabalhos vêm explorando o vigor híbrido da cultura do arroz para aumentar a competitividade dessa cultura com as plantas daninhas (Balbinot Jr. et al., 2003; Galon et al., 2007). Plantas híbridas normalmente possuem crescimento mais rápido e vigoroso, ocupando a área primeiro que a maioria das plantas daninhas, reduzindo sua interferência sobre as plantas da cultura (Balbinot Jr. et al., 2003).

A principal forma de interferência que se estabelece entre o arroz irrigado e as plantas daninhas é a competição por luz e nutrientes, constituindo-se em um dos principais fatores limitantes da produtividade nas lavouras de arroz irrigado do Rio Grande do Sul e de Santa Catarina (Andres \& Machado, 2004; SOSBAI, 2007). Em lavouras conduzidas no sistema convencional, a competição por água é relevante nos primeiros 30 dias após a emergência e pode determinar o potencial produtivo de uma área. Em situações de limitação hídrica, plantas mais eficientes na extração da água, ou capazes de tolerar a deficiência, tendem a se estabelecer melhor na área.

A eficiência do uso da água é caracterizada como a quantidade de água transpirada por uma cultura para a produção de certa quantidade de matéria seca (Silva et al., 2007). Assim, culturas mais eficientes no uso da água podem produzir quantidade maior de matéria seca por grama de água transpirada. O uso mais eficiente da água está diretamente relacionado ao tempo de abertura estomática, pois, enquanto a planta absorve $\mathrm{CO}_{2}$ para a fotossintese, a água é perdida por transpiração, com intensidade variável, dependendo do gradiente de potencial entre a superficie foliar e a atmosfera, seguindo uma corrente de potenciais hídricos (Concenço et al., 2007).
Uma das opções para melhorar a utilização do recurso água pode ser a escolha de cultivares mais eficientes quanto ao uso desta para a produção da parte econômica, e em especial o arroz irrigado (Baptista et al., 2001), classificado como muito exigente quanto à água durante o ciclo (Noldin et al., 2001). Quando plantas estão submetidas à alta competição, as características fisiológicas do crescimento e desenvolvimento normalmente são alteradas, o que resulta em diferenças no aproveitamento dos recursos do ambiente, principalmente no uso da água, que influencia de modo direto a disponibilidade de $\mathrm{CO}_{2}$ no mesofilo foliar, a temperatura da folha e, consequentemente, a eficiência fotossintética da planta (Radosevich et al., 1997).

Objetivou-se com este trabalho avaliar as características associadas à eficiência de uso da água em variedade de arroz híbrida e convencional, de forma a detectar qual variedade apresenta maior capacidade de aproveitamento desse recurso.

\section{MATERIAL E MÉTODOS}

O experimento foi instalado na Universidade Federal de Viçosa, Viçosa-MG, entre novembro de 2006 e janeiro de 2007, em casa de vegetação com irrigação por aspersão, em delineamento experimental de blocos casualizados, com esquema de tratamentos fatorial $2 \times 6$ e quatro repetições. As unidades experimentais constaram de vasos de $13 \mathrm{~L}$, preenchidos com substrato - mistura préelaborada de solo e terra vegetal, sendo corrigido o $\mathrm{pH}$ e adubado de acordo com análise de solo e as recomendações técnicas da cultura do arroz (SOSBAI, 2007). Os tratamentos constaram de uma planta de arroz da variedade BRS Pelota (convencional) ou Inov (híbrida) no centro da unidade experimental, que competia com número variável de plantas da variedade BRS Pelota na periferia da parcela. No centro da unidade experimental foram distribuídas três sementes de arroz da variedade que representa o tratamento, enquanto na periferia da unidade experimental foram distribuídas seis sementes da variedade BRS Pelota, de acordo com os tratamentos propostos (Figura 1). O processo de semeadura foi realizado no mesmo dia para ambas as variedades. 


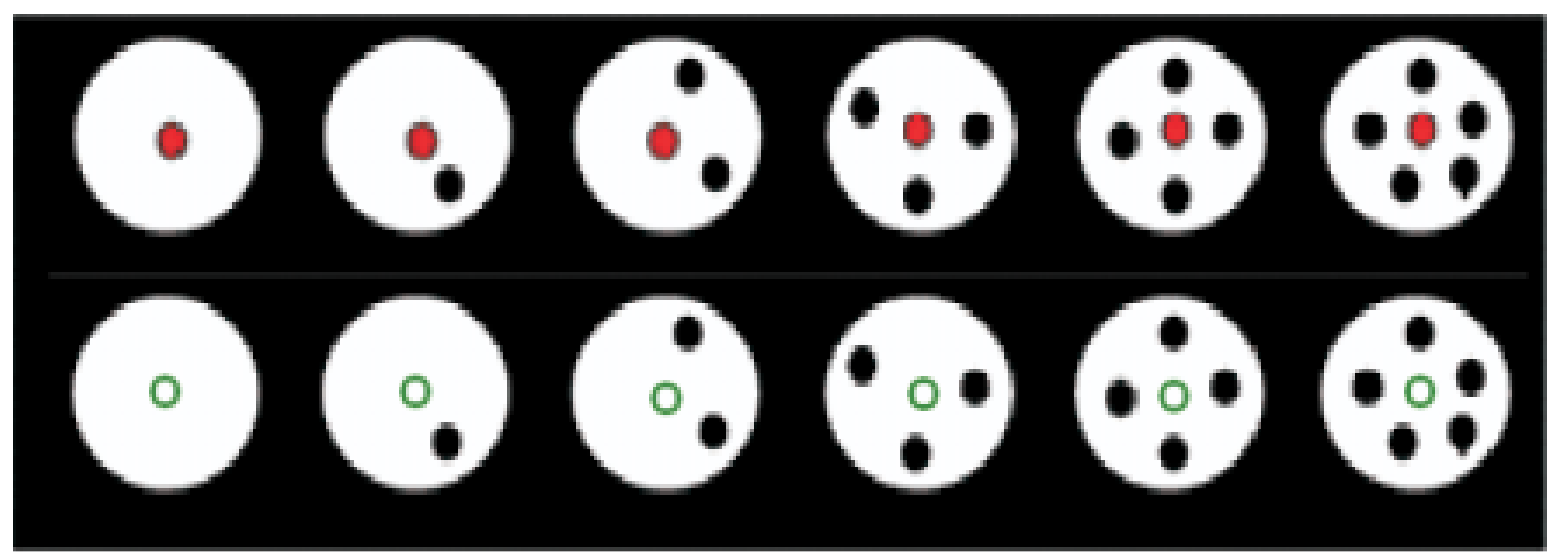

Figura 1 - Disposição dos tratamentos em condição de casa de vegetação. (•) planta de arroz BRS Pelota avaliada; (O) planta de arroz Inov avaliada; $(\bullet)$ planta de arroz BRS Pelota promotora da competição.

As plântulas foram desbastadas aos 10 dias após a emergência (DAE). Os tratamentos consistiram em manter uma planta no centro da unidade experimental, variando na periferia as densidades entre 0 e 5 plantas da variedade BRS Pelota, de acordo com o tratamento. A área de semeadura da planta de arroz foi delimitada por círculo de $5 \mathrm{~cm}$ de diâmetro por $2 \mathrm{~cm}$ de profundidade, que possibilitou a identificação da planta adulta, juntamente com seus respectivos perfilhos, sem interferir na competição da planta central com as demais da periferia, tanto na parte aérea quanto no sistema de raízes.

As unidades experimentais foram mantidas equidistantes, de forma que a área de superficie disponivel para o desenvolvimento das plantas correspondesse à área da unidade experimental. Aos 50 DAE foram realizadas as avaliações, no terço médio da primeira folha completamente expandida do perfilho principal das plantas de arroz. Foi utilizado um analisador de gases no infravermelho (IRGA LCA $\mathrm{Pro}^{+}$) em casa de vegetação aberta, permitindo livre circulação do ar. Também se coletou a parte aérea das plantas, e posteriormente o material foi seco em estufa de circulação forçada de ar a $60{ }^{\circ} \mathrm{C}$ até massa constante; elas foram pesadas em balança analitica, onde se obteve a variável massa seca da parte aérea (MSPA). Cada bloco foi avaliado em um dia, entre 8 e 10 horas da manhã, de forma a manter as condições ambientais homogêneas durante a avaliação.
Além da massa seca de plantas, avaliouse também a condutância estomática de vapores de água (Gs - $\mathrm{mol} \mathrm{m}^{-1} \mathrm{~s}^{-1}$ ), a temperatura da folha $\left({ }^{\circ} \mathrm{C}\right)$, a taxa de transpiração $\left(\mathrm{E}-\mathrm{mol} \mathrm{H}_{2} \mathrm{O} \mathrm{\textrm {m } ^ { 2 }} \mathrm{s}^{-1}\right)$ e a eficiência do uso da água (WUE - $\mathrm{mol} \mathrm{CO}_{2} \mathrm{~mol} \mathrm{H}_{2} \mathrm{O}^{-1}$ ) obtida pela relação entre quantidade de $\mathrm{CO}_{2}$ fixado pela fotossintese e quantidade de água transpirada.

Os dados foram submetidos à análise de variância pelo teste $\mathrm{F}$ e, em caso de significância, efetuou-se o teste de Duncan, para avaliar o efeito do aumento na densidade de plantas, e o teste da Diferença Mínima Significativa (DMS), para comparar as variedades na mesma intensidade de competição, em cada tratamento. Todos os dados foram analisados a $5 \%$ de probabilidade.

\section{RESULTADOS E DISCUSSÃO}

A massa seca da parte aérea de ambas as variedades estudadas foi menor com o aumento na intensidade de competição. Plantas isoladas apresentaram massa seca superior à das demais com maior intensidade de competição. Da mesma forma, as variedades híbrida e convencional não diferiram quanto ao acúmulo de massa seca em nenhum dos tratamentos estudados (Tabela 1).

Pode-se inferir que a competição intraplanta, ou seja, entre os órgãos da mesma planta de arroz, foi relevante na determinação do acúmulo de massa, conforme já relatado em 
outros trabalhos (Radosevich et al., 1997; Fleck et al., 2008). É possivel especular que plantas da variedade híbrida tenham favorecido o crescimento em altura em detrimento do acúmulo de massa em folhas, como forma de se sobressair à imposição da competição. Aspiazú et al. (2008) relatam que plantas de capim-arroz (Echinochloa crusgalli), quando apresentaram a mesma massa seca sob competição, diferiram quanto à capacidade competitiva em função da partição de fotoassimilados. Essas plantas obtiveram maior acúmulo de massa seca em colmos em detrimento das folhas, como forma de evitar a competição por luz quando em alta densidade, ou seja, com plantas de características morfofisiológicas similares.

De maneira geral, o gradiente entre a temperatura da folha e a do ar (Tabela 2) aumentou de acordo com o incremento na intensidade de competição entre as plantas, em ambas as variedades estudadas. O metabolismo do vegetal causa incremento na temperatura da folha, de forma que, via de regra, a temperatura da folha é superior à temperatura do ar ao seu redor. Dessa forma, incrementos no metabolismo podem ser indiretamente aferidos em função do gradiente entre a temperatura da folha e a do $\operatorname{ar}(\Delta \mathrm{T})$. Normalmente essa diferença é de somente um ou dois graus, mas em casos extremos pode exceder a $5{ }^{\circ} \mathrm{C}$ (Drake \& Salisbury, 1972; Atkin et al., 2000). Na ausência de competição, plantas híbridas tenderam a apresentar temperatura da folha

Tabela 1 - Massa seca da parte aérea (g por planta) de plantas de arroz irrigado, em função de variedade e intensidade de competição em ambiente controlado, aos 50 dias após emergência

\begin{tabular}{|c|c|c|c|}
\hline \multirow{2}{*}{$\begin{array}{c}\text { MSPA } \\
\text { Tratamento }\end{array}$} & \multicolumn{2}{|c|}{ Variedade de Arroz } & \multirow{2}{*}{ Diferença ${ }^{2}{ }^{2}$} \\
\cline { 2 - 3 } & BRS Pelota & Inov & \\
\hline $1:(0)$ & $36,58 \mathrm{a}^{1 /}$ & $36,48 \mathrm{a}$ & $0,1 \mathrm{~ns}$ \\
\hline $1:(1)$ & $13,10 \mathrm{~b}$ & $12,28 \mathrm{~b}$ & $0,82 \mathrm{~ns}$ \\
\hline $1:(2)$ & $8,76 \mathrm{~b}$ & $6,99 \mathrm{~b}$ & $1,77 \mathrm{~ns}$ \\
\hline $1:(3)$ & $6,33 \mathrm{~b}$ & $6,47 \mathrm{~b}$ & $-0,14 \mathrm{~ns}$ \\
\hline $1:(4)$ & $5,84 \mathrm{~b}$ & $5,66 \mathrm{~b}$ & $0,18 \mathrm{~ns}$ \\
\hline $1:(5)$ & $4,47 \mathrm{~b}$ & $5,17 \mathrm{~b}$ & $-0,7 \mathrm{~ns}$ \\
\hline
\end{tabular}

1/ Médias seguidas da mesma letra, na coluna, não diferem pelo teste de Duncan a $5 \%$ de probabilidade; ${ }^{2} /$ ns - não significativo pelo teste da DMS a $5 \%$ de probabilidade. mais alta que a observada em plantas convencionais, o que indica maior atividade metabólica e pode estar relacionado diretamente à maior taxa fotossintética, ou à maior eficiência de uso da água (Larcher, 2006) por plantas híbridas. A $\Delta \mathrm{T}$ mostrou significância, confirmando desse modo que o metabolismo foi afetado e que esse fator provavelmente não possa ser excluído da participação na condutância estomática.

Quanto à condutância estomática (Gs) de vapores de água (Tabela 3), plantas convencionais não diferiram da testemunha com planta isolada, quando competindo com somente uma planta da mesma variedade. No entanto, a partir da competição com duas

Tabela 2 - Gradiente térmico folha - ar $\left({ }^{\circ} \mathrm{C}\right)$ de plantas de arroz irrigado, em função de variedade e intensidade de competição em ambiente controlado, aos 50 dias após emergência

\begin{tabular}{|c|c|c|c|}
\hline \multirow{2}{*}{$\begin{array}{c}\text { Delta T } \\
\text { Tratamento }\end{array}$} & \multicolumn{2}{|c|}{ Variedade de Arroz } & \multirow{2}{*}{ Diferença $^{2}{ }^{2 /}$} \\
\cline { 2 - 3 } & BRS Pelota & Inov & \\
\hline $1:(0)$ & $0,35 \mathrm{c}^{\mathrm{1} /}$ & $0,53 \mathrm{bc}$ & $-0,18 \mathrm{~ns}$ \\
\hline $1:(1)$ & $0,50 \mathrm{c}$ & $0,28 \mathrm{c}$ & $0,22 \mathrm{~ns}$ \\
\hline $1:(2)$ & $0,75 \mathrm{bc}$ & $0,40 \mathrm{c}$ & $0,35 \mathrm{~ns}$ \\
\hline $1:(3)$ & $0,83 \mathrm{bc}$ & $0,60 \mathrm{bc}$ & $0,23 \mathrm{~ns}$ \\
\hline $1:(4)$ & $0,93 \mathrm{~b}$ & $0,88 \mathrm{~b}$ & $0,05 \mathrm{~ns}$ \\
\hline $1:(5)$ & $1,48 \mathrm{a}$ & $1,43 \mathrm{a}$ & $0,05 \mathrm{~ns}$ \\
\hline
\end{tabular}

1/ Médias seguidas da mesma letra, na coluna, não diferem pelo teste de Duncan a $5 \%$ de probabilidade; ${ }^{2 /}$ ns - não significativo pelo teste da DMS a 5\% de probabilidade.

Tabela 3 - Condutância estomática de vapores de água $\left(\mathrm{mol} \mathrm{m} \mathrm{m}^{-1} \mathrm{~s}^{-1}\right)$ de plantas de arroz irrigado, em função de variedade e intensidade de competição em ambiente controlado, aos 50 dias após emergência

\begin{tabular}{|c|c|c|c|}
\hline \multirow{2}{*}{$\begin{array}{c}\text { Gs } \\
\text { Tratamento }\end{array}$} & \multicolumn{2}{|c|}{ Variedade de Arroz } & \multirow{2}{*}{ Diferença ${ }^{2 /}$} \\
\cline { 2 - 3 } & BRS Pelota & Inov & \\
\hline $1:(0)$ & $4,55 \mathrm{a}^{1 /}$ & $1,29 \mathrm{~b}$ & $3,26^{*}$ \\
\hline $1:(1)$ & $3,64 \mathrm{a}$ & $1,89 \mathrm{ab}$ & $1,75^{*}$ \\
\hline $1:(2)$ & $1,45 \mathrm{~b}$ & $2,84 \mathrm{a}$ & $-1,39 *$ \\
\hline $1:(3)$ & $2,00 \mathrm{~b}$ & $1,11 \mathrm{~b}$ & $0,89 \mathrm{~ns}$ \\
\hline $1:(4)$ & $0,53 \mathrm{~b}$ & $1,01 \mathrm{~b}$ & $-0,48 \mathrm{~ns}$ \\
\hline $1:(5)$ & $0,36 \mathrm{~b}$ & $0,16 \mathrm{c}$ & $0,20 \mathrm{~ns}$ \\
\hline
\end{tabular}

1/'Médias seguidas da mesma letra, na coluna, não diferem pelo teste de Duncan a $5 \%$ de probabilidade; $\stackrel{2 /}{n s}$ - não significativo pelo teste da DMS a $5 \%$ de probabilidade. 
plantas, a condutância de vapores de água foi menor que a observada nos demais tratamentos. Para a variedade híbrida, não foram observadas diferenças até a densidade de 1:(2), ou seja, uma planta da variedade híbrida competindo com duas plantas da variedade convencional. Isso pode ser indicativo de que plantas híbridas podem ter a capacidade de, pelo menos, se igualar em capacidade competitiva quando competindo com o dobro da densidade de plantas convencionais em determinada área. Por exemplo, em uma área com 300 plantas de arroz $\mathrm{m}^{-2}$, 100 plantas da variedade híbrida poderiam competir com igualdade contra 200 plantas da variedade convencional BRS Pelota pelo recurso água. Quando as plantas foram diretamente comparadas na mesma intensidade de competição, pôde-se observar que, sob menores intensidades competitivas, plantas híbridas apresentaram menor condutância estomática de vapores de água, indicativo de que possam ser mais eficientes na utilização deste recurso, uma vez que não foram observadas diferenças quanto ao acúmulo de massa seca nessa situação (Tabela 1).

A intensidade transpiratória (E) não foi alterada em plantas convencionais até intensidades de competição de quatro plantas periféricas da variedade BRS Pelota competindo com a planta central da mesma variedade. Somente na maior intensidade de competição avaliada a transpiração de plantas convencionais foi inferior à dos demais tratamentos (Tabela 4). A variedade híbrida, no entanto, mostrou maiores intensidades transpiratórias nos tratamentos $1:(1), 1:(2)$ e $1:(3)$, o que é indicativo de maior intensidade de perda de água e possibilidade de menor eficiência de uso da água sob essas condições. Contudo, em algumas situações a menor eficiência de uso da água pode estar relacionada à maior capacidade de captura de $\mathrm{CO}_{2}$ pela planta, pois, enquanto os estômatos estão abertos e a água é perdida por transpiração, $\mathrm{o} \mathrm{CO}_{2}$ entra na folha e pode ser incorporado na forma de glicose (Taiz \& Zeiger, 2006).

A condutância foliar é composta em pequena parte pela condutância cuticular da epiderme e, quando os estômatos estão abertos, pela Gs, que é controlada pelas célulasguarda dos estômatos. Assim, a Gs é proporcional ao número e tamanho dos estômatos
Tabela 4 - Taxa transpiratória $\left(\mathrm{mol}_{2} \mathrm{O} \mathrm{m}^{-2} \mathrm{~s}^{-1}\right)$ de plantas de arroz irrigado, em função de variedade e intensidade de competição em ambiente controlado, aos 50 dias após emergência

\begin{tabular}{|c|c|c|c|}
\hline \multirow{2}{*}{$\begin{array}{c}\text { E } \\
\text { Tratamento }\end{array}$} & \multicolumn{2}{|c|}{ Variedade de Arroz } & \multirow{2}{*}{ Diferença ${ }^{2 /}$} \\
\cline { 2 - 3 } & BRS Pelota & Inov & \\
\hline $1:(0)$ & $3,48 \mathrm{a}^{1 /}$ & $3,34 \mathrm{~b}$ & $0,14 \mathrm{~ns}$ \\
\hline $1:(1)$ & $3,30 \mathrm{a}$ & $3,91 \mathrm{a}$ & $-0,61 \mathrm{~ns}$ \\
\hline $1:(2)$ & $2,92 \mathrm{a}$ & $4,07 \mathrm{a}$ & $-1,15^{*}$ \\
\hline $1:(3)$ & $2,95 \mathrm{a}$ & $3,75 \mathrm{a}$ & $-0,80 *$ \\
\hline $1:(4)$ & $2,90 \mathrm{a}$ & $2,99 \mathrm{~b}$ & $-0,09 \mathrm{~ns}$ \\
\hline $1:(5)$ & $1,93 \mathrm{~b}$ & $1,56 \mathrm{c}$ & $0,37 \mathrm{~ns}$ \\
\hline
\end{tabular}

1/ Médias seguidas da mesma letra, na coluna, não diferem pelo teste de Duncan a $5 \%$ de probabilidade; ${ }^{2 /}$ ns - não significativo pelo teste da DMS a $5 \%$ de probabilidade.

e diâmetro da abertura do estômato, caracteristicas que dependem de outros fatores endógenos e ambientais (Brodribb \& Holbrook, 2003). A água só é perdida por transpiração enquanto os estômatos estão abertos. O controle da abertura e o fechamento dos estômatos dependem de uma série de fatores, como radiação solar, nível de $\mathrm{CO}_{2}$ no mesofilo, umidade relativa (déficit de pressão de vapor do ar), potencial hídrico e outros de menor magnitude, como vento, substâncias de crescimento e ritmos endógenos próprios de cada espécie.

A maior intensidade transpiratória pode não indicar, necessariamente, menor eficiência no uso da água por essa planta. A maior perda de água por transpiração pode decorrer da maior necessidade dessa planta de incorporar $\mathrm{CO}_{2}$, em função da alta atividade fotossintética que ela pode apresentar. Além do exposto, plantas da variedade híbrida apresentaram maior taxa transpiratória nas intensidades medianas de competição. Em decorrência disso, é possível especular que plantas da variedade híbrida podem estar aumentando a intensidade fotossintética e, consequentemente, transpiratória, como forma de se sobressair em relação às plantas da variedade convencional (Tabela 4). É possivel inferir ainda que existe relação causal entre a condutância estomática e a intensidade transpiratória, pois onde a condutância estomática iniciou a estabilização (Tabela 3) a intensidade transpiratória começou a se elevar na variedade híbrida acima do observado 
para as variedades convencionais. Provavelmente, concomitantemente com a intensidade transpiratória, tenha ocorrido proporcional aumento na taxa fotossintética dessas plantas.

O declínio de transpiração está associado ao fechamento dos estômatos, e variações na abertura estomática causam alterações no potencial hídrico, por atuarem sobre a $\mathrm{E}$ (Brodribb \& Hill, 2000). A planta tende a fechar os estômatos quando os níveis de luz estão abaixo da radiação fotossinteticamente ativa, ou para evitar o estresse hídrico (Cochard et al., 2002). Todos esses parâmetros estão ligados em relação de custo/benefício, pois a $\mathrm{E}$ também é um mecanismo de diminuir a $\Delta \mathrm{T}$. Os processos de transpiração e captura de $\mathrm{CO}_{2}$ só ocorrem quando os estômatos estão abertos, bem como a Gs. Devido ao calor latente de evaporação (o calor que efetivamente é usado para "aquecer" a água e possibilitar a evaporação), a transpiração tem um poderoso efeito resfriador, importante na regulação da $\Delta \mathrm{T}$ (Farquhar \& Raschke, 1978).

A eficiência do uso da água (Tabela 5) não foi alterada em plantas da variedade convencional em função do aumento da intensidade de competição (Tabela 5), permanecendo com valor médio de 3,99 mol de $\mathrm{CO}_{2}$ incorporado por mol de $\mathrm{H}_{2} \mathrm{O}$. A variedade híbrida, Inov, foi idêntica à BRS Pelota quanto à eficiência do uso da água nas intensidades intermediárias de competição (Tabela 5); ao confrontar esta informação com a maior perda de água por transpiração (Tabela 4), pode-se aferir indiretamente

Tabela 5 - Eficiência de uso da água $\left(\mathrm{mol} \mathrm{CO}_{2} \mathrm{~mol} \mathrm{H}_{2} \mathrm{O}^{-1}\right)$ de plantas de arroz irrigado, em função de variedade e intensidade de competição em ambiente controlado, aos 50 dias após emergência

\begin{tabular}{|c|c|c|c|}
\hline \multirow{2}{*}{$\begin{array}{c}\text { EUA } \\
\text { Tratamento }\end{array}$} & \multicolumn{2}{|c|}{ Variedade de Arroz } & \multirow{2}{*}{ Diferença ${ }^{2}{ }^{2}$} \\
\cline { 2 - 3 } & BRS Pelota & Inov & \\
\hline $1:(0)$ & $4,42 \mathrm{a}^{1 /}$ & $6,18 \mathrm{~b}$ & $-1,76^{*}$ \\
\hline $1:(1)$ & $3,49 \mathrm{a}$ & $4,36 \mathrm{c}$ & $-0,87 \mathrm{~ns}$ \\
\hline $1:(2)$ & $4,05 \mathrm{a}$ & $4,55 \mathrm{c}$ & $-0,5 \mathrm{~ns}$ \\
\hline $1:(3)$ & $3,57 \mathrm{a}$ & $3,93 \mathrm{c}$ & $-0,36 \mathrm{~ns}$ \\
\hline $1:(4)$ & $3,85 \mathrm{a}$ & $4,14 \mathrm{c}$ & $-0,29 \mathrm{~ns}$ \\
\hline $1:(5)$ & $4,59 \mathrm{a}$ & $7,97 \mathrm{a}$ & $-3,38 *$ \\
\hline
\end{tabular}

1/ Médias seguidas da mesma letra, na coluna, não diferem pelo teste de Duncan a $5 \%$ de probabilidade; $\stackrel{2 /}{n s}$ - não significativo pelo teste da DMS a 5\% de probabilidade. que plantas híbridas apresentaram vantagem na taxa fotossintética em relação às plantas convencionais, pois a eficiência de uso da água é obtida pela razão entre a fotossíntese e a transpiração. No entanto, nas condições deste experimento, a massa seca de ambas as plantas foi similar. Plantas da variedade híbrida se destacaram quanto à eficiência de uso da água quando isoladas ou sob alta intensidade de competição, quando a interferência mútua entre as plantas menos competitivas as prejudica e as plantas com maior capacidade de crescimento provavelmente sobressaem.

Plantas da variedade híbrida balancearam melhor as variáveis associadas à eficiência do uso da água que plantas da variedade convencional. Em situações favoráveis ao desenvolvimento ou sob alta intensidade competitiva, plantas híbridas se destacam em relação às convencionais. Nas condições deste experimento, plantas da variedade híbrida foram superiores ou não diferiram das convencionais quanto à eficiência do uso da água. Em lavouras de arroz conduzidas no sistema convencional de semeadura no Sul do Brasil, por exemplo, as plantas se desenvolvem sob elevado déficit hídrico nos primeiros 20 a 30 dias após a semeadura - esta característica pode ocasionar vantagens para as plantas híbridas de arroz em relação às convencionais.

\section{LITERATURA CITADA}

ANDRES, A.; MACHADO, S. L. O. Plantas daninhas em arroz irrigado. In: GOMES, A.S.; MAGALHÃES JR.; A. M. (Eds.). Arroz Irrigado no Sul do Brasil. Brasília: Embrapa Informação Tecnológica, 2004. p. 457-546.

ASPIAZÚ, I. et al. Relação colmos/folhas de biótipos de capim-arroz em condição de competição. R. Trópica, v. 1, n. 2 , p. $22-30,2008$

ATKIN, O. K. et al. Leaf respiration of Snow Gum in the light and dark. Interactions between Temperature and Irradiance. Plant Physiol., v. 122, n. 3, p. 915-923, 2000.

BALBINOT Jr., A. A. et al. Competitividade de cultivares de arroz irrigado com cultivar simuladora de arroz-vermelho. Pesq. Agropec. Bras., v. 38, n. 1, p. 53-59, 2003.

BAPTISTA, J. M. et al. Programa nacional para o uso eficiente da água. Lisboa: Instituto Superior de Agronomia, 2001. 212 p. 
BRODRIBB, T. J.; HILL, R. S. Increases in water potential gradient reduce xylem conductivity in whole plants. Evidence from a low-pressure conductivity method. Plant Physiol., v. 123 , n. 3 , p. $1021-1028,2000$

BRODRIBB, T. J.; HOLBROOK, N. M. Stomatal closure during leaf dehydration, correlation with other leaf physiological traits. Plant Physiol., v. 132, n. 4, p. 2166-2173, 2003.

COCHARD, H. et al. Unraveling the effects of plant hydraulics on stomatal closure during water stress in walnut. Plant Physiol., v. 128, n. 1, p. 282-290, 2002.

CONCENÇO, G. et al. Uso da água em biótipos de azevém (Lolium multiflorum) em condição de competição. Planta

Daninha, v. 25, n. 3, p. 449-455, 2007.

DRAKE, B. G.; SALISBURY, F. B. Aftereffects of low and high temperature pretreatment on leaf resistance, transpiration, and leaf temperature in Xanthium. Plant Physiol., v. 50, n. 5, p. 572-575, 1972.

FARQUHAR, G. D.; RASCHKE, K. On the resistance to transpiration of the sites os transpiration within the leaf. Plant Physiol., v. 61, n. 6, p. 1000-1005, 1978

FLECK, N. G. et al. Competitividade relativa entre cultivares de arroz irrigado e biótipos de arroz-vermelho. Planta

Daninha, v. 2, n. 1, p. 101-111, 2008.

GALON, L. et al. Níveis de dano econômico para decisão de controle de capim-arroz (Echinochloa spp.) em arroz irrigado (Oryza sativa). Planta Daninha, v. 25, n. 4, p. 709-718, 2007.
LARCHER, W. Ecofisiologia vegetal. São Carlos: Rima, 2006. $753 \mathrm{p}$.

MELO, P. T. B. S. et al. Comportamento de populações de arroz irrigado em função das proporções de plantas originadas de sementes de alta e baixa qualidade físiológica. R. Bras. Agroci., v. 12, n. 1, p. 37-43, 2006.

NOLDIN, J. A. et al. Persistência do herbicida clomazone no solo e na água quando aplicado na cultura do arroz irrigado, sistema pré-germinado. Planta Daninha, v. 19, n. 3, p. 401-408, 2001.

RADOSEVICH, S.; HOLT, J.; GHERSA, C. Weed ecology implications for management. New York: Willey \& Sons, 1997. 589 p.

SINCLAIR, T. R. et al. Water use efficiency of field-grown maize during moisture stress. Plant Physiol., v. 56, n. 2, p. $245-249,1975$.

SILVA, A. A. et al. Competição entre plantas daninhas e culturas. In: SILVA, A. A.; SILVA, J. F. (Eds.). Tópicos em manejo de plantas daninhas. Viçosa, MG: Universidade Federal de Viçosa, 2007. p. 17-61.

SOSBAI. Arroz irrigado: Recomendações técnicas da pesquisa para o Sul do Brasil. Itajaí: 2007. 126 p.

TAIZ, L.; ZEIGER, E. Plant physiology. Sunderland: Sinauer, 2006. 705 p. 